\title{
IMPORTÃNCIA DAS PEQUENAS EMPRESAS INDUSTRIAIS NO PROBLEMA DE ACIDENTES DO TRABALHO EM SÃO PAULO*
}

MENDES, R. - Importancia das pequenas empresas industriais no problema de acidentes do trabalho em São Paulo. Rev. Saúde públ., S. Paulo, 10:315-25, 1976.

Resumo: Após análise das medidas legais recentemente introduzidas no Brasil para controle do problema de acidentes do trabalho, é verificada a distribuição dos acidentes de acordo com o tamanho das empresas, em número de empregados. Foram analisados 6.033 "acidentes graves" ocorridos em São Paulo, no periodo de 1969 a 19\%4, comparando-se sua distribuição com a da mäo-de-obra industrial, no mesmo periodo. Verificon-se, então, que o "risco" de acidentes nas pequenas empresas (menos de 100 empregados) é 1.96 rezes - das empresas médias (100 a 499 empregados) ou 3,77 vezes o das empresas grandes (500 e mais empregados). Sugere-se uma politica de prevenção de acidentes do trabalho para pequenas empresas.

Unitermos: Acidentes do trabalho. Pequenas empresas, Saide ocupacional.

INTRODUCAO

Ao lado dos inegáveis benefícios trazidos pelo recente desenvolvimento econômico do Brasil, vêm emergindo em escala crescente, problemas intimamente dependentes do binômio industrialização-urbanização, destacando-se, entre eles, a poluição ambiental e os infortúnios do trabalho, representados, estes últimos, pelos acidentes do trabalho e pelas doenças profissionais ${ }^{30}$.

Quanto aos acidentes do trabalho e às doenças profissionais, vem aumentando o número absoluto de ocorrências, o núme- ro relativo (proporção de acidentes em relação ao número de empregados segurados) e o custo direto, pago pela Previdência Social, como pode ser observado na Tabela 1.

Para fazer frente a esta tendência socialmente indesejável e economicamente onerosa, o Governo Federal vem aperfeiçoando os instrumentos de que dispõe, através do Ministério da Previdência e Assistência Social e do Ministério do Trabalho. Assim, entre estas medidas, a Portaria Ministerial MTPS n. ${ }^{\circ} 3.237$, de 27

- Resumo da Dissertação de Mestrado apresentada à Faculdade de Saúde Pública da Unlversidade de São Paulo, 1975.

* Do Departamento de Medicina Preventiva da Escola Paulista de Medicina - Rua Botucatu, 720 - São Paulo, SP - Brasil; da Superintendência de Avaliação do Ruído e Qualidade do Ar, da Companhia Estadual de Tecnologia de Saneamento Básico e de Defesa do Meio Ambiente (CETESB) - Av. Prof. Frederico Herman Júnior, 345 - São Paulo, SP - Brasil. 
MENDES, R. - Importância das pequenas empresas inđustriais no problema de acidentes do trabalho em Săo Paulo. Rev. Saúde públ., S. Paulo, 10:315-25, 1976.

T A B EL A 1

Evolução dos acidentes do trabalho no Brasil, 1969-74

\begin{tabular}{c|c|c|c|c}
\hline Ano & $\begin{array}{c}\text { Número de } \\
\text { empregados }\end{array}$ & $\begin{array}{c}\text { Número de } \\
\text { acidentes }\end{array}$ & $\mathbf{A} / \mathrm{E} \times 100$ & $\begin{array}{c}\text { Custo segurado* } \\
\text { (Cr\$) }\end{array}$ \\
\hline 1969 & $\mathbf{7 . 2 6 8 . 4 4 9}$ & $\mathbf{1 . 0 5 9 . 2 9 6}$ & 14,57 & $\mathbf{2 6 9 . 5 4 4 . 5 2 2 , 0 0}$ \\
1970 & $\mathbf{7 . 2 8 4 . 0 2 2}$ & $\mathbf{1 . 2 2 0 . 1 1 1}$ & $\mathbf{1 6 , 7 5}$ & $\mathbf{4 7 5 . 3 5 2 . 6 2 5 , 0 0}$ \\
1971 & $\mathbf{7 . 5 5 3 . 4 7 2}$ & $\mathbf{1 . 3 2 6 . 4 7 3}$ & 17,56 & $679.055 .859,00$ \\
1972 & $\mathbf{8 . 3 0 0 . 5 0 9}$ & $\mathbf{1 . 5 0 4 . 7 2 3}$ & $\mathbf{1 8 , 1 3}$ & $\mathbf{8 6 7 . 5 1 1 . 4 5 3 , 0 0}$ \\
1973 & 10.956 .956 & 1.632 .696 & $\mathbf{1 4 , 9 0}$ & $\mathbf{1 . 3 0 4 . 6 8 0 . 2 0 0 , 0 0}$ \\
1974 & $11.500 .000 * *$ & 1.796 .761 & 15,62 & $\mathbf{2 . 0 1 3 . 6 5 8 . 7 2 6 , 0 0}$
\end{tabular}

Fonte: Mensário Estatistico do Instituto Nacional de Previdência Social (INPS).

- Estima-se que o custo total seja cinco vezes malor.

** Estimativa.

de julho de $1972^{\circ}$, ao regulamentar o Artigo 164 da Consolidação das Leis do Trabalho, tornou obrigatória a existência de Serviços Especializados em Segurança, Higiene e Medicina do Trabalho, em estabelecimentos definidos de acordo com o número de empregados e com o grau de risco específico da atividade.

Segundo aquele diploma legal, tal como já ocorria com as CIPAs - Comissões Internas de Prevenção de Acidentes a obrigatoriedade iniciava-se com $101 \mathrm{em}$ pregados, pelo menos nos estabelecimentos classificados como "grande risco". Aliás, tal classificação deu-se através da Portaria DNSHT n. ${ }^{\circ} 17$, de 25 de julho de $1973^{\circ}$, que incluiu a maioria das indústrias de transformação nesta categoria de risco.

Embora seja reconhecido o mérito destas iniciativas, devem ser lembradas suas limitações, principalmente por terem ficado excluídas de qualquer sistema de atenção especializada em Saúde Ocupacional as empresas com 100 ou menos empregados. Especificamente em relação aos estabelecimentos industriais, o Censo Industrial do $\mathrm{IBGE}^{22}$ mostra que as pequenas empresas no Brasil (menos de 100 empregados) significam $97,27 \%$ dos estabelecimentos e $46,5 \%$ da mão-de-obra industrial. Dados mais recentes e preci- sos $^{43}$ confirmam para o Estado de São Paulo, proporçōes não muito diferentes: $96,45 \%$ e $31,49 \%$, respectivamente.

Mais recentemente, a Portaria Ministerial MTb n..$^{\circ} 3.460$, de 31 de dezembro de $1975^{10}$, ao revogar a Portaria MTPS 3.237 antes referida, bem como as portarias complementares que se seguiram (3.089, de 2 de abril de 1973; 17, de 25 de julho de $1973 ; 40$, de 31 de dezembro de 1973), introduziu importantes modificações quanto à abrangência da obrigatoriedade de Serviços de Segurança, Higiene e Medicina do Trabalho nas empresas.

As principais modificações dizem respeito à classificação de riscos e ao número de empregados onde se inicia a obrigatoriedade de pessoal especializado. Os Quadros II, III e IV da Portaria n. ${ }^{\circ} 3.460$ mostram que entre 101 e 500 empregados, tão somente os estabelecimentos classificados em "risco 4" são obrigados a ter profissionais de nível superior, especializados em Saúde Ocupacional, mesmo assim, em tempo parcial.

$O$ estudo paralelo destes quadros e da Tarifa Oficial de Contribuição - TOC ${ }^{28}$ - que serve como base para esta classificação, bem como do Censo Industrial do IBGE - $1970^{22}$, permite observar que nåo mais que $6,9 \%$ do universo de es- 
MENDES, R. - Importância das pequenas empresas industriais no problema de acidentes do trabalho em São Paulo. Rev. Saúde públ., S. Paulo, 10:315-25, 1976.

tabelecimentos industriais no Brasil classificar-se-iam naquele grau. Excluindo-se as empresas com menos de 100 empregados e as com mais de 500 , esta proporção reduz-se a cerca de $0,16 \%$, o que em 1970 não chegaria a 300 estabelecimentos.

Assim, a Portaria n. ${ }^{\circ} 3.460^{10}$, ao excluir a obrigatoriedade de Serviços Especializados em Segurança, Higiene e Medicina do Trabalho nas empresas pequenas e médias, e ao deixar de prever para este porte de empresas qualquer sistema de atenção específica em Saúde Ocupacional, fez com que $99,6 \%$ dos estabelecimentos industriais e $76 \%$ da mão-de-obra industrial do Brasil, permaneçam à margem do mais importante instrumento de que o Governo lançou mão, para conter os alarmantes índices de acidentes do trabalho.

Como se isto não bastasse, tanto o empirismo quanto a observação da literatura estrangeira $28,38,39$, permitem suspeitar que nestes estabelecimentos, principalmente nos menores, más condições de Saúde Ocupacional, decorrentes de inúmeros fatores resultantes da interação agente-hospedeiro-meio, traduzam-se por uma maior incidência de acidentes de trabalho, em relação às ocorrências nos estabelecimentos de maior porte.

$\mathrm{Na}$ ausência de uma comprovação objetiva e quantificada - menos empírica - da pior situação das pequenas empresas no Brasil, em relação aos acidentes do trabalho, sua verificação passou a tornar-se objetivo deste trabalho.

\section{MATERIAL E METODOS}

Não existindo, habitualmente, a informação sobre o tamanho da empresa, em número de empregados, nos registros de acidentes do trabalho, tiveram de ser analisados processos de "acidentes graves", onde este dado está presente, preenchido, aliás, pelo funcionário que inicia o processo de investigação a que tais acidentes são submetidos. São analisados assim.
6.033 acidentes do trabalho, considerados "graves", ocorridos na Grande São Paulo, no período de 1969 a 1974, cujos processos encontram-se arquivados na Coordenação Regional de Ácidentes do Trabalho, da Superintendência Regional do INPS.

Como acidente do trabalho foi adotado o conceito legal, expresso pela Lei $n .^{\circ}$ 5.316 , de 14 de setembro de $1967^{7}$. Como acidente grave teve-se de aceitar o critério interno da referida Coordenação, que, de modo geral, compreende o acidente que levou a óbito, a incapacidade permanente, ou que se constituiu de lesóes graves, tais como fraturas, perdas de substância, etc., as doenças profissionais - todos que a critério daquela Coordenação são passíveis da prevenção de sua repetição e cuja investigação seja proveitosa para essa finalidade. Excluíram-se, deste critério, os acidentes ocorridos na Construção Civil, os de trânsito e os de trajeto.

Os acidentes graves foram distribuídos segundo o tamanho da empresa onde ocorreram, em três estratos (pequena, média e grande empresa) e em sete estratos (1 a $4 ; 5$ a $9 ; 10$ a $19 ; 20$ a $49 ; 50$ a $99 ; 100$ a $499 ; 500$ ou mais empregados).

Com base no Cadastro Industrial do SENAI ${ }^{43}$, por onde se tem a distribuição da mão-de-obra industrial na capital de São Paulo (julho-1972/junho-1973), o número de acidentes em cada estrato foi dividido pelo número de empregados no respectivo estrato, considerando-os pessoas potencialmente expostas ao risco de se acidentar, naquele estrato. Os quocientes destas divisões foram comparados entre si, ou seja, calcularam-se "riscos relativos" para os diferentes estratos.

\section{RESULTADOS E DISCUSSÃO}

Os resultados alcançados constam nas Tabelas 2 e 3 . 
MENDES, R. - Importância das pequenas empresas industriais no problema de acidentes do trabalho em São Paulo. Rev. Saúde públ., S. Paulo, 10:315-25, 1976.

TABELA 2

Distribuição dos empregados em estabelecimentos industriaîs e dos acidentes graves. segundo o tamanho da empresa (em 3 estratos) - 1972-73

\begin{tabular}{|c|c|c|c|c|c|}
\hline $\begin{array}{l}\text { Tamanho da } \\
\text { empresa }\end{array}$ & Empregados & Acidentes & $\begin{array}{c}\text { Acid./emp. } \\
\text { (x 100) }\end{array}$ & \multicolumn{2}{|c|}{$\begin{array}{c}\text { Proporção de } \mathrm{A} / \mathrm{E} \text {, em } \\
\text { relação às "grandes } \\
\text { empresas" }\end{array}$} \\
\hline \multicolumn{6}{|l|}{ Pequenas } \\
\hline$\left(\begin{array}{lll}1 & \text { a } & 99\end{array}\right)$ & 216.966 & 3.115 & 1,435 & 3,77 & 1 \\
\hline $\begin{array}{l}\text { Médias } \\
(100 \text { a } 499)\end{array}$ & 271.448 & 1.982 & 0,730 & 1,92 & 1 \\
\hline $\begin{array}{l}\text { Grandes } \\
(500 \text { e }+)\end{array}$ & 245.736 & 936 & 0,380 & 1 & 1 \\
\hline Total & 734.150 & 6.033 & 0,821 & 2,16 & 1 \\
\hline
\end{tabular}

* Fonte: Cadastro Industrial do SENAI *3.

TABELA 3

Distribuição dos empregados em estabelecimentos industriais e dos acidentes graves, segundo o tamanho da empresa (em 7 estratos) - 1972-73

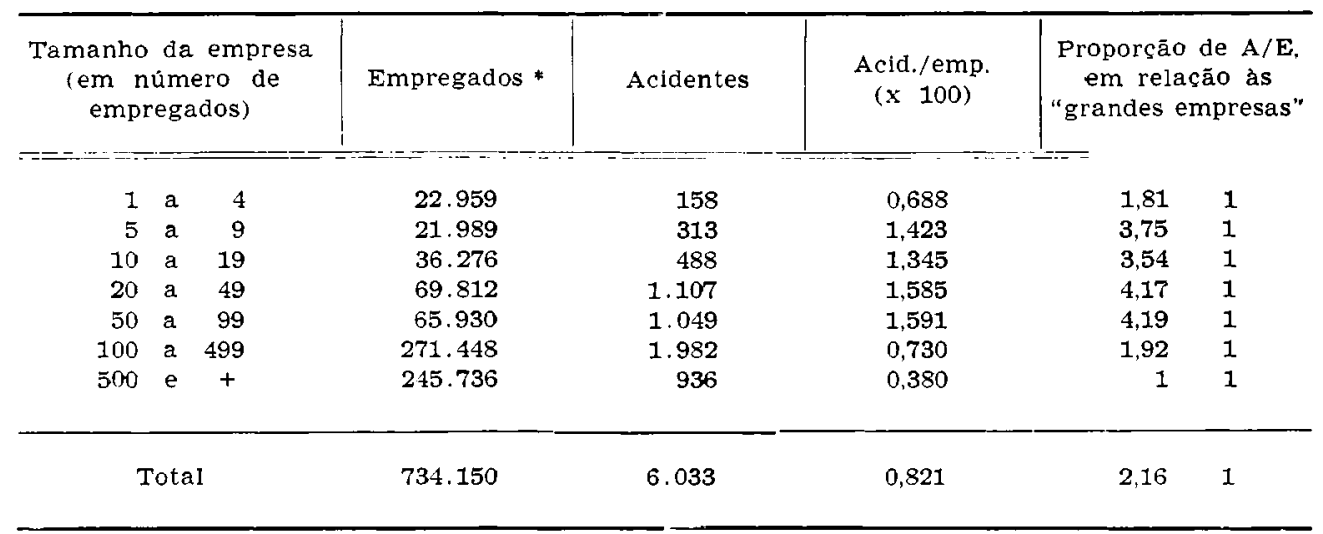

* Fonte: Cadastro Industrial do SENAI ${ }^{33}$.

A distribuição dos acidentes segundo - tamanho da empresa somente torna-se válida quando correlacionada com o número de empregados em cada estrato, o que permite criar uma proporção ou coeficiente. Para os objetivos deste trabalho, não está em jogo a magnitude absoluta das proporções obtidas. mas sim, sua comparação, já que os critérios para sua ohtenção foram os mesmos.

A comparação destas proporções gera uma unidade semelhante ao "risco relativo", tão comum na metodologia epidemiológica. Assim, observa-se na Tabela 2. que o "risco" de ocorrência de acidentes do trabalho (pelo menos os "graves") 
MENDES, R. - Importância das pequenas empresas industriais no problema de acidentes do trabalho em são Paulo. Rè. Salide pübl, S. Paulo. 10:315-25, 1976.

nas pequenas empresas, é 3.77 vezes o das grandes. enquanto o risco das médias é 1.92 vezes o das grandes.

Outro modo de destacar esta nítida tendência de maior ocorrência de acidentes nas pequenas empresas é. a partir dos dados da Tabela 2, comparar a distribuição percentual da mão-de-obra industrial, com a dos acidentes. estrato por estrato, o que é feito na Tabela 4.

\section{TABELA 4}

Distribuiçāo percentual da mão-de-obra industrial na capital de São Paulo e de 6.033 acidentes graves, segundo o tamanho das empresas - 1972-73

\begin{tabular}{|c|c|c|}
\hline $\begin{array}{c}\text { Tamanho da } \\
\text { empresa }\end{array}$ & $\begin{array}{c}\text { Empre- } \\
\text { gados * } \\
\left(\sigma_{6}\right)\end{array}$ & $\begin{array}{c}\text { Acidentes } \\
\left(C_{0}\right)\end{array}$ \\
\hline Pequenas & 29.5 & 51,7 \\
\hline Médias & 37,0 & 32,8 \\
\hline Grandes & 33.5 & 15,5 \\
\hline Total & 100,0 & 100,0 \\
\hline
\end{tabular}

* Fonte: Cadastro Industrial do SENAI ${ }^{43}$.

O mesmo tratamento pode ser dispensado aos dados da Tabela 3. obtendo-se a Tabela 5 .

Evidencia-se. assim, de modo claro, que os acidentes do trabalho, pelo menos os graves, são muito mais freqüentes nas pequenas empresas industriais. que nas médias. e nestas. mais freqüentes que nas grandes. traduzindo más condições de Saúde Ocupacional. o que aliás. era nossa hipótese.

A inferência prática imediata é a de que o prohlema dos acidentes do trabalho. como um todo. tem localização acentuadamente forte nas indústrias com menos de 100 empregados. sugerindo que a política nacional de prevenção de acidentes deva concentrar sua atenção para este porte de empresas.

\section{TABELA 5}

Distribuiçōes percentuais do número de pessoas empregadas em estabelecimentos industriais na capital de São Paulo e de 6.033 acidentes graves, segundo o tamanho da empresa - 1972-73

\begin{tabular}{|c|c|c|}
\hline $\begin{array}{l}\text { Tamanho da } \\
\text { empresa } \\
\text { (em número de } \\
\text { empregados) }\end{array}$ & $\begin{array}{l}\text { Empre- } \\
\text { gados * } \\
\text { (co) }\end{array}$ & $\begin{array}{c}\text { Acidentes } \\
(\%)\end{array}$ \\
\hline $1 \mathrm{a}$ & 3.1 & 2,6 \\
\hline $\begin{array}{lll}5 & \text { a } & 9\end{array}$ & 3,0 & 5,2 \\
\hline 10 a 19 & 4,9 & 8,2 \\
\hline 20 a 49 & 9.5 & 18,3 \\
\hline $\begin{array}{lll}50 & \text { a } & 99\end{array}$ & 9,0 & 17,4 \\
\hline 100 a 499 & 37,0 & 32,8 \\
\hline $500 e+$ & 33,4 & 15.5 \\
\hline Total & 100,0 & 100,0 \\
\hline
\end{tabular}

É compreensível. no entanto. que as más condições de Saúde Ocupacional reinantes nas pequenas empresas. traduzidas aqui pela ocorrência mais acentuada de acidentes graves. não podem ser encaradas como um problema isolado. de Higiene e Segurança do Trabalho. São sim. um indicador das más condições gerais e de outras caracteristicas tradicionalmente descritas nas pequenas empresas. tais como: a) pequena especialização na administração: b) inadequação dos métodos de produção: (') ineficiência e obsoletismo do equipamento industrial; d) inadequação das instalaçôes físicas: el escassa qualificação da mão-de-obra: f) escassa visão empresarial $1,4,4,11,12,19, \cdots 34,35,40,41,45$.

Em virtude de tal complexidade "causal". a abordagem preventiva tamliém não pode ser feita parcialmente. com os escassos instrumentos que possui a Higiene e Segurança do Trahalho. A ahordagem preventiva está intimamente relacionada a fatores ambientais ou físicos próprios das 
MENDES, R. - Importancia das pequenas empresas industriais no problema de acidentes do trabalho em São Paulo. Rev. Saúle públ., S. Paulo, 10:315-25, 1976.

fábricas. aos equipamentos, ao comportamento do empresário, ao comportamento do empregado e depende, naturalmente, de insumos humanos e técnicos e. principalmente, financeiros, geralmente fora do alcance das pequenas empresas.

Por esta razão, a política de prevenção de acidentes para pequenas empresas, deveria estar intimamente relacionada com a política de assistência técnico-financeira para estas empresas, já relativamente bem estruturada no Brasil. Assim, vários órgãos de economia mista e privados vêm se dedicando a esta tarefa $2,3,5,13,14,15$, 16. $17,18,21,23,24,25,26,27,31,32,36,42$. 44. 46,47 .

Os programas de assistência financeira tomaram corpo com a criação do Banco Tacional de Desenvolvimento Econômico - BNDE --, seguida da criação de ban$\cos$ de desenvolvimento regionais ou estaduais. Em 1965, o BNDE criou o FIPEME - Fundo de Financiamento à Pequena e Média Empresas - atualmente POC - Programa de Operaçōes Conjuntas - que tem como objetivos:

-- estimular o desenvolvimento econômico do pais, especificamente através das pequenas e médias indústrias:

- atenuar as diferenças setoriais e regionais observadas no desenvolvimento econômico; e

- fomentar a exportação de produtos industriais.

Os pedidos de financiamento são apresentados através de projetos, seguindo roteiro fornecido pelo BNDE e agentes repassadores, dependendo a aprovação dos projetos. principalmente da gestão empresarial. Os recursos do FIPEME são, basicamente, provenientes da dotação do próprio BNDE e, em menor escala, de empréstimos especiais contratados com o Banco Interamericano de Desenvolvimento - BID - e Kreditanstald für $\mathbb{W}_{\text {ie- }}$ deraufbau - KfW - , da Alemanha Ocidental.

Em 1972, foi criado o Centro Brasileiro de Assistência Gerencial à Pequena e Média Empresas - CEBRAE - órgão vinculado ao então Ministério do Planejamento e Coordenação Geral, tendo ainda como membros-fundadores o BNDE, a Financiadora de Estudos e Projetos S.A. FINEP e a Associação Brasileira de Bancos de Desenvolvimento - ABDE.

O CEBRAE é uma entidade civil, sem fins lucrativos, cabendo-lhe promover, com a co-participação de entidades coordenadoras, a assistência para a prestação de serviço de organização empresarial, em todos os seus aspectos - tecnológico, econômico, financeiro, administrativo como também assistência para a formação. treinamento e aperfeiçoamento de pessoal técnico-administrativo e de dirigentes de empresas.

Na área do Polígono das Secas, a SLDENE. do Ministério do Interior, com recursos financeiros do Banco do Nordeste do Brasil - BNB - tem sua política regional de assistência às pequenas e médias empresas, abrangendo a assistência financeira (através de uma rede estadual de agentes repassadores) e a assistência técuica. através dos Núcleos de Assistência Industrial - NAIs. Os NAIs foram sendo instituídos mediante convênios firmados entre a SLDENE e entidades estaduais diversas, como Universidades $\mathrm{Fe}$ derais. Federação das Indústrias, Bancos e Companhias Estaduais, Secretarias de Indústria e Comércio, ete.

Em São Paulo, o Centro de Assistência Gerencial à Pequena e Média Empresa do Estado de São Paulo - CEAG-SP visa. especialmente, a coordenar e promover recursos para os trabalhos de vários núcleos que se dedicam ou que vierem a se dedicar àquela atividade no Estado, evitando que. de um lado, por falta de meios. tais programas sejam inibidos ou não tenham o devido alcance, bem como que. de outro. os recursos financeiros e humanos canalizados para esse campo se 
MENDES, R. - Importância das pequenas empresas industriais no problema de acidentes do trabalho em São Paulo. Rev. Saúde públ., S. Paulo, 10:315-25, 1976.

dispersem em iniciativas paralelas ou insuficientes para a problemática ser atendida.

O CEAG-SP ,assim, náo pretende executar diretamente nenhum trabalho de assistência gerencial, devendo sua função ser mais de motivação e de disciplinamento. Ele aprecia, aprova e encaminha ao CEBRAE projetos dessa natureza, elahorados e a serem executados pelos mais variados núcleos autônomos entre si. A cobertura de custo é assim distribuída: $60 \%$ a CEBRAE, $20 \%$ a CEAG-SP e $20 \%$ ao núcleo executivo.

Por sua vez, com recursos estaduais do Fundo de Apoio ao Contribuinte FUNAC - e recursos federais do BNDE e CEBRAE, drenados através do CEAG, a Secretaria da Fazenda mantém o PROPEME - Programa Especial de Crédito Orientado para Pequenas e Médias Empresas. A assistência baseia-se em crédito concedido após análise da empresa e elaboração de um diagnóstico integrado, que indicará a efetiva necessidade da empresa, quanto ao capital de giro e inversões fixas exigidas para o desenvolvimento das atividades. 0 empresário deve acompanhar a execução deste diagnóstico e posteriormente receber, dos analistas do Programa, orientação para encontrar soluçôes alternativas que resultem no aprimoramento técnico e econômico de sua empresa. A assistência técnica visa, basicamente, ao aumento de produtividade das empresas assistidas, e perdura, inclusive, durante a vigência do contrato.

Frente a tão amplo espectro de atenção para pequenas empresas, sugere-se a vinculaçâao destes programas de crédito orientado, à melhoria das condições de Saúde Ocupacional, de tal forma que as instituiçōes que executam estes programas, façam incluir em suas equipes, profissionais especializados em Higiene e Segurança do Trabalho, cabendo-lhes: a) participar das visitas técnicas à empresa solicitante do programa; b) participar da elaboração do diagnóstico empresarial; c) prestar assistência técnica durante a vigência do programa.

Por outro lado, a Recomendação $n .^{\circ}$ 112 da Organização Internacional do Trabalho - $1959^{37}$ —, ratificada pelo Brasil, ao tratar dos Serviços de Saúde Ocupacional nas empresas, apresenta a modalidade de serviços comuns a várias pequenas empresas, agrupadas por critério geográfico ou setorial. Esta experiência, com as suas naturais limitaçōes, tem-se mostrado satisfatória nos países altamente industrializados e mesmo em países em desenvolvimento ${ }^{20}, 29,38,39$.

Basicamente, estes Serviços de Saúde Ocupacional para pequenas empresas assemelham-se pela sua natureza e pelas atividades que desenvolvem. A maior parte deles está diretamente vinculada a um órgão público, geralmente Ministério do Trabalho ou da Saúde, compóe-se de empresas agrupadas voluntária ou compulsoriamente, segundo critério geográfico ou setorial, tem administração própria supervisionada por representantes das empresas cooperadoras, as quais colaboram no custeio, proporcionalmente ao número de empregados.

As atividades são, evidentemente, menos complexas que as constantes na Recomendação n. 112 (item 7) da OIT ${ }^{37}$, sendo desdobradas em "essenciais" e em "desejáveis".

De um modo geral, as atividades de Saúde Ocupacional consideradas "essenciais" são:

a) visitação dos locais de trabalho, para recomendação de medidas de prevenção, e vigilância de implantação dessas medidas, visando à proteção dos trabalhadores contra os possíveis riscos à saúde, decorrentes do seu trabalho ou das condições em que este é realizado;

b) realização de exames médicos pré-admissionais, exames médicos periódicos (a todos os empregados ou apenas àqueles expostos a riscos espe- 
MENDES, R. - Importancia das pequenas empresas industriais no problema de acidentes do trabalho em São Paulo. Rev. Saúde públ., S. Paulo, 10:315-25, 1976.

ciais), exames médicos especiais a trabalhadores menores, idosos, subnormais ou por ocasião do retorno ao trabalho, após ausência por doença ou por acidente;

c) organização de facilidades para primeiros socorros;

d) atividades de educação sanitária.

No caso do Brasil, a Consolidação das Leis do Trabalho (CLT) prevê, em seu Artigo 164, que as empresas que se enquadram em determinadas condições são obrigadas a manter Serviço Especializado em Segurança e Higiene do Trabalho. A regulamentação deste artigo da CLT foi feita através de uma série de portarias recentes mencionadas na introdução, estando em vigor a de $n .^{\circ} 3.460$, de 31 de dezembro de $1975^{10}$. Como já foi salientado, a obrigatoriedade destes serviços praticamente inicia-se com 500 empregados, ou seja, restringe-se às grandes empresas. Ao contrário da Recomendação n. ${ }^{0} 112 \mathrm{da}$ OIT ${ }^{37}$, nada é previsto para as empresas de menor porte.

A segunda sugestão para a política de atenção aos problemas de Saúde Ocupacional em pequenas empresas no Brasil, diz respeito à regulamentação da opção de Serviços de Saúde Ocupacional de natureza interempresarial, desde que se enquadre em uma das seguintes situações:

- ser instituição sem fins lucrativos, do tipo cooperativa;

- ser instituição da administração pública direta ou indireta, preferentemente vinculada ao Ministério do Trabalho;

- ser instituição sindical, de empregados ou de empregadores.

Devem ser excluídas da possibilidade de criar tais serviços, as instituiçôes de fins comerciais, como são os "grupos mé- dicos", pelas naturais contraindicações de sobejo conhecidas.

\section{CONCLUSOES}

1. Entre os acidentes do trabalho que ocorrem na Grande São Paulo, pelo menos os "acidentes graves" são muito mais frequientes nas pequenas empresas (menos de 100 empregados) que nas médias (100 a 499 empregados), e nestas, mais frequientes que nas grandes (500 ou mais empregados) :

- O "risco" de ocorrência de acidentes graves nas pequenas empresas industriais é 3,77 vezes o da ocorrência nas grandes empresas. 0 "risco" de ocorrência de acidentes graves nas pequenas empresas industriais é 1,96 vezes o da ocorrência nas médias empresas. Nestas, o "risco" é 1,92 vezes o de ocorrência nas grandes empresas.

- Enquanto as pequenas empresas ocupam $29,5 \%$ da mão-de-obra industrial, nelas ocorrem $51,7 \%$ dos acidentes graves. Ao contrário, enquanto as grandes empresas ocupam $33,5 \%$ da mão-deobra industrial, nelas ocorrem apenas $15,5 \%$ dos acidentes graves.

2. A importância das pequenas empresas na ocorrência de acidentes "graves" na Grande São Paulo, permite suspeitar que as empresas deste porte também estejam pesando, de modo acentuado, no problema de acidentes do trabalho, como um todo no Brasil.

3. Para a redução do problema de acidentes do trabalho no Brasil, impóe-se a introdução de uma política de atenção em Higiene, Segurança e Medicina do Trabalho, especialmen- 
MENDES, R. - Importância das pequenas empresas industrials no problema de acidentes do trabalho em são Paulo. Rev. Saúde públ., S. Paulo, 10:315-25, 1976.

te destinada às pequenas empresas, que leva em conta soluções como:

- participação do sistema de assistência técnica e financeira a pequenas empresas, já existente no Brasil; revisão dos critérios de obrigatoriedade de Serviços Especializados em Segurança, Higiene e Medicina do Trabalho nas empresas, regulamentando, adequadamente, a alternativa de Serviços Interempresas.

RSPU-B/326

MENDES, R. - [Importance of small factories in occupational accidents in $S$. Paulo, Brazil]. Rev. Saúde públ., S. Paulo, 10:315-25, 1976.

SUMmary: After a discussion on the legal means recently adopted in Brazil aiming at the control of occupational accidents, the distribution of the latter according to the size of the organizations was studied. 6,310 serious occupational injuries which took place in the City of São Paulo between 1969 and 1974 were studied and distributed in "small" (up to 100 employees), "medium" (from 100 to 499) and "large" (500 and more) industries. The "small" group is further subdivided into five strata: 1 to 4,5 to 9,10 to 19,20 to 49 and 50 to 99 employees. The ratio of the number of accidents over the number of employees in each stratum shows that the risk in small industries, as compared to others, is $3.7 \gamma$ times higher, than that which is observed in large industries and 1.96 times the risk in the medium ones. The latter show a risk 1.92 higher than the former. Detailed comments on these results are followed by a policy recommendation for the prevention of occupational accidents in small industries, through the establishment of an Inter-Undertaking Health Service (administered by non-profit organizations) and the incorporation of technical aspects of occupational hygiene and safety in government loan plans for small industries in Brazil.

UNITERMS: Accidents, industrial. Industries, small. Occupational health. Accidents occupational.

\section{REFERENCIAS BIBLIOGRAFICAS}

1. ALMEIDA, J. - Industrialização e emprego no Brasil. Rio de Janeiro, Inst. de Planejamento Econômico e Social, 1971. (Relatório de Pesquisa, 24).

2. APOIO do BNDE a pequenas e médias indústrias no Brasil. Rev. BNDE, Rio de Janeiro, 10(1/2):3-32, 1973.

3. ASSISTENCIA à pequena e média indústria. Indústr. \& Produtiv., 5(52): 25-6, 1972.

4. BARROS, F. J. O. R. \& MODENESI, R. L. - Pequenas e médias indústrias: análise dos problemas, incentivos e sua contribuiça ao desenvolvimento. Rio de Janeiro, Inst. de Planejamento Econômico e Social, 1973. (Relatório de Pesquisa, 17).
5. BARROS SOBRINHO, M. J. F. - Oportunidade para novas indústrias pequenas e médias. Aratu - Um Polo em Desenvolvimento, Salvador, $\mathbf{3}(26)$ : 34-6, 1969.

6. BOUZAN, A. et al. - Aspectos legais $e$ económicos da pequena empresa brasileira. Rio de Janeiro, Fundacão Getúlio Vargas, 1968. (FGV. Série Administração na Pequena Empresa, 3).

7. BRASIL. Leis, decretos, etc. - Acidentes, Seguranç, Higiene e Medicina do Trabalho: coletanea de leis, decretos e portarias; compilação pelo Dr. Eduardo Gabriel Saad. 2.a ed. São Paulo, Fundacentro, 1972. (Serie Legislação, 1). 
MENDES, R. - Importância das pequenas empresas industriais no problema de acidentes do trabaho em são Paulo. Rer. Salue públ., S. Paulo, 10:31j-25, 1976.

8. BRASIL. Leis, decretos, etc. - Portaria no 3.237 de 27 de julho de 1972 , do Sr. Ministro de Estado do Trabalho e Previdência Social. Diário Oficial, $2 / 14$ ago. 1972

9. BRASIL. Leis, decretos, etc. - Portaria $\mathrm{n}^{\circ} 17$, de 25 de julho de 1973 , do Diretor Geral do DNSHT. Diário Oficial, 28 ago. 1973.

10. BRASIL. Leis, decretos, etc. - Portaria n. 3.460 . de 31 de dezembro de 1975 , do $\mathrm{Sr}$. Ministro de Estado do Trabalho. Diario Oficial, $31 \mathrm{dez}$. 1975.

11. CARDOSO, S. S. - Algumas consideracōes sobre a pequena e média empresas no Brasil. Rev. BNDE, Rio de Janeiro, $8(1 / 2): 51-5,1971$.

12. CarvalHo, L. C. P. - Problemas das pequenas e médias empresas. Econ. paul., $5(56 / 57): 2-7,1974$.

13. CHALmers, R. B. - Contribuição de marketing para o desenvolvimento das pequenas e médias empresas. Induistr. e Desenv., 2(11):24-5, 1969.

14. DELGADO, J. L. - Crescer ou desaparecer, alternativas das pequenas empresas industriais. Indistr. e Desenv., $4(10): 16-9,1971$.

15. DELGADO, P. L. - Manual de procedimentos de organizaça e administracão para pequenas e médias empresas industriais. São Paulo, NAM$\mathrm{PE}, 1972$.

16. Delgado, P. L. - Pequenas empresas são necessárias. Indiustr. e Desenv., 4 (3) : 21-2, 1971.

17. DELGADO, P. L. - Vez da pequena e mẻdia empresas. Indüstr. e Desenv., $3(7): 18-20,1970$.

18. DESENVOLVIMENTO das pequenas e médias empresas. Econ. paul., 4: $(46 / 47): 2-8, \quad 1973$

19. DIAGNóSTICO da pequena e média empresa, Rev. Ass. Com. $R$. Janeiro, $35(1064 / 1065): 4-10,13-8,1973$.

20. ESPANHA. Instituto Nacional de Prevision. Los servicios de medicina y seguricad del trabajo en las pequeñas empresas. Madrid, Secretaria General Técnica, Servicio de Información e Estudios, 1966.

21. FREITAS, S. G. - Medidas de fomento a pequenas empresas. Indústr, $\boldsymbol{e}$ Desenv., 4(9):20-2, 1971.

22. FUNDAÇAO IBGE, Censo industrial de Süo Paulo. Rio de Janeiro, 1974. (VIII Recenseamento Geral, 1970. Série Nacional)

23. FCNDEPRO beneficia igualmente grandes e pequenas empresas. Dirig. industr., São Paulo, 20:220-6, 1970.

24. FUNDO DE FINANCIAMENTO DA PEQUENA E MÉDIA EMPRESA (FIPEME). Capital de giro para a pequena e média empresa, sint. industr., Rio de Janeiro, (9):5-6, 1967.

25. GIR, X. - Formação de dirigentes para as pequenas e médias indústrias. Indistr. \& Produtiv., 1(9):22-38, 1969.

26. HOLTZ, R. - A importância e as condições de desenvolvimento das pequenas e médias empresas. Induistr. de Produtiv., 1(2):42-5, 1968.

27. HORA e vez das pequenas e médias indústrias. Econ. paul., 1(6):15-9, 1970.

28. INPS - Tarifa Oficial de Contribuicões - Orientação de Serviço do INPS n. ${ }^{\circ}$ SAF 299.75 de 27-12-74.

29. JOINT WHO/ILO SEMINAR ON HEALTH SERVICES IN SMALL FACTORIES. Dun Laoghaire, Ireland, 8-16 May 1961. Report. Copenhagen, World Health Organization, Regional office for Europe, 1963. (ONS/EURO-196).

30. LAURENTI, R. - o problema das doenças crônicas e degenerativas e dos acidentes nas areas urbanizadas da América Latina. Rev. Saúde puibl., S. Paulo, 9:239-48, 1975 .

31. LIMA, J. L. - O BN.B. e a pequena e média indústria no nordeste. Econ. e Desenv., (10):55-66, 1970.

32. LIMA NETTO, R. P. - Politica para pequena e média empresa. Rev. $B N D E$, Rio de Janeiro, 8(1/2):45-50, 1971. 
MENDES, R. - Importância das pequenas empresas industriais no problema de acidentes do trabalho em São Paulo. Rev. Salide públ., S. Paulo, 10:315-25, 1976.

33. LOFTUS, R. - Problemas de gestão das pequenas indústrias. Indústr. \& Produtiv., 1(10):10-18, 1969 .

34. LOPES, C - Tratamento injusto da pequena indústria. Dirig. industr., São Paulo, 10(1):98, 1968.

35. MACHLINE, C. et al. - Administraçāo da produção na pequena empresa brasıleira. Rio de Janeiro, Fundação Getúlio Vargas, 1966. (FGV. Série Administração na Pequena Empresa, 1).

36. Nova fase do pequeno e médio empresariado. Planej. \& Desenv., 1(2): 58-61, 1973.

37. ORGANIZACÁO INTERNACIONAL DO TRABALHO. Recomendación sobre los servicios de medicina del trabajo en los lugares de empleo (recom. n. ${ }^{\circ} 112$ da OIT adoptada em 24 jun. 1959). In: ORGANIZAÇAO INTERNACIONAL DO TRABALHO - Convenios $y$ recomendaciones (19191966). Ginebra, 1966. p. 1054-8.

38. ORGANIZAÇAO INTERNACIONAL DO TRABALHO - Au service de la petite industrie. Genève, 1971. (OIT - Etudes et Documents - Nouvelle Série, 61).

39. ORGANIZAÇO INTERNACIONAL DO TRABALHO - Los servicios de medicina del trabajo en los paises en vias de desarrollo. Ginebra, 1967. (Serie Seguridad, Higiene y Medicina del Trabajo, 7).
40. PEQUENAS e médias indústrias de auto. peças. Programa Delf. São Paulo, Dep. de Publicaçōes da Fac. de Ciências Econômicas e Administrativas da LSP, 1967. 2 v.

41. PEQUENAS e médias indústrias têxteis. Programa Delf. São Paulo, Dep. de Publicações da Fac. de Ciências Econômicas e Administrativas da USP, 1968. 3 v.

42. PROGRAMA de financiamento à pequena e média empresas. Rev. $B N D E$, Rio de Janeiro, 1:415-6, 1964.

43. RELATORIO DO SENAI: 1973. São Pau10, 1973 p. 261-75.

44. ROCCA, C. A. - Novos horizontes para a pequena e média empresa. Mundo econ., São Paulo, 5(9):51-9, 1973.

45. SAO PAULO. Assessoria de Política Econômica. Grupo de Descentralização Industrial Algumas observações sobre a pequena e média indústria paulista. Econ. paul., 1(5):43-7, 1970.

46. A VEZ da pequena empresa. SUDENE Inf., Recife, 6:4-6, 1968.

47. YUE, C. J - Hora e vez das pequenas e médias indústrias. Econ. paul., 1 (6) :15-9, 1970

Recebido para publicacão em 06/05/1976 A provado para publicacão em 14/06/1796 